\title{
Study On Spatio-Temporal Evolution of Habitat Quality Based On Land-Use Change In Chongming Dongtan, China
}

\section{Sheng Li}

Anhui Agricultural University

Bin Dong ( $\sim 19810986187 @ 139 . c o m$ )

Anhui Agricultural University

\section{Xiang Gao}

Anhui Agricultural University

\section{Haifeng Xu}

Anhui Agricultural University

\section{Chunqiu Ren}

Anhui Agricultural University

Yaru Liu

Anhui Agricultural University

Liang Peng

Anhui Agricultural University

\section{Research Article}

Keywords: Land use change, InVEST model, Habitat quality, Chongming Dongtan

Posted Date: August 4th, 2021

DOl: https://doi.org/10.21203/rs.3.rs-750293/v1

License: (9) This work is licensed under a Creative Commons Attribution 4.0 International License.

Read Full License

Version of Record: A version of this preprint was published at Environmental Earth Sciences on April 1st, 2022. See the published version at https://doi.org/10.1007/s12665-022-10324-w. 


\title{
Study on Spatio-temporal Evolution of Habitat Quality
}

\section{Based on Land-use Change in Chongming Dongtan, China}

\author{
Sheng $\mathrm{Li}^{1}$, Bin Dong ${ }^{* 1}$, Xiang Gao ${ }^{1}$, Haifeng Xu ${ }^{1}$, Chunqiu Ren ${ }^{1}$, Yaru Liu ${ }^{1}$, Liang \\ Peng ${ }^{1}$ \\ (1.School of Science, Anhui Agricultural University, Hefei 230036, Anhui, China)
}

\begin{abstract}
Chongming Dongtan is an important habitat for international migratory birds. It is of great significance to study its land use and habitat quality change for rare waterfowl protection and ecological environment restoration. Based on the land use data in 2002, 2012 and 2020, this paper analyzes the relationship between land use change and habitat quality evolution in Chongming Dongtan in recent 18 years by using InVEST model, land use dynamic degree and land use degree index. The results show that the main types of land use in the study area are water area and cultivated land, followed by woodland, reed beach, grass beach, bare beach and construction land. Among them, bare beach and construction land have changed dramatically, the former continuing to decrease while the latter continuing to increase. And the increasing speed began to slow down after 2012, and the increasing part was mainly from the surrounding cultivated land. Secondly, in terms of time change, the degradation of habitat quality in Chongming Dongtan has been gradually improved from aggravating trend in the past 18 years. In terms of spatial distribution, the habitat degradation degree of Chongming Dongtan is higher in the east and lower in the west, spreading from the center to the surrounding. Based on this, the change of land use and the interference of human activities are the important reasons for the change of ecological environment quality.
\end{abstract}

Keywords : Land use change; InVEST model; Habitat quality; Chongming Dongtan

\section{Introduction}

Habitat quality refers to the ability of the ecosystem to provide suitable individuals and populations with sustainable survival and reproduction within a certain space and time range, and is an important ecosystem service. Stable habitat quality is an important basis for maintaining biodiversity of the ecosystem, which reflect regional biodiversity to a certain extent ${ }^{[1-2]}$. Studies have shown that land use change is the main driving force of habitat quality change. By changing the ecosystem structure and function, land use change causes the fragmentation and loss of species and effective habitats of the ecosystem, and then leads to habitat degradation ${ }^{[3]}$. Therefore, the evaluation of habitat quality based on land use change can not only clarify whether the land use pattern and intensity within the study area are reasonable, but also help to reveal the change law and driving mechanism of habitat quality in the study area, which has important scientific significance for promoting regional ecological protection and sustainable development ${ }^{[4]}$.

InVEST (Integrated Valuation of Ecosystem Services and Tradeoffs) was jointly organized and developed by Stanford University, The Nature Conservance and Century Nature 
Foundation. Habitat Quality module in the model has been widely used by scholars at home and abroad to evaluate Habitat Quality. For example, foreign scholars used InVEST model to evaluate the temporal and spatial variation of habitat quality in the Nile Basin of the Ethiopian Plateau and its relationship with landscape characteristics ${ }^{[5]}$, the change of habitat quality in Jeju Island ${ }^{[6]}$, and the habitat environment of amphibians in the North American prairie ${ }^{[7]}$. At present, habitat quality assessment based on land use change and revealing the impact of land use change on habitat quality have become one of the research hot-spots ${ }^{[8]}$. Liu Fangtian et al. ${ }^{[9]}$ used InVEST model combined with Markov model to quantitatively evaluate the habitat quality of Xinjiang Corps and non-Corps and the evolution of habitat quality caused by land use change. Wang Geng et al. ${ }^{[10]}$ used GIS technology and InVEST model to conduct quantitative assessment of habitat quality in coastal areas of Dandong, and analyzed the impact of land use change on habitat quality in combination with the law of land use change. Huang Muyi et al. ${ }^{[11]}$ analyzed the spatial and temporal evolution of habitat quality and the interaction and gradient effect of landscape pattern based on InVEST model and topographic position method in the Dabie Mountain in western Anhui Province. Han Yanli et al. ${ }^{[12]}$ used InVEST model and "3S" technology to quantitatively estimate the habitat quality in the Qinghai Lake Basin, analyzed the temporal and spatial distribution characteristics of habitat quality in the Qinghai Lake Basin, and revealed the impact of land use change on habitat quality in the basin.

Chongming Dongtan, located at the estuary of the Yangtze River, is an internationally important estuarine tidal flat wetland, as well as an important post station and wintering habitat on the migration route of global migratory birds "East Asia - Australia", among which Chongming Dongtan Bird National Nature Reserve is located ${ }^{[13]}$. As one of the most important ecologically sensitive regions in the world, Chongming Dongtan is rich in natural resources and has an extremely important ecological location. Therefore, it is of great significance to evaluate the habitat quality based on land use change and reveal the impact of land use change on the habitat quality of Chongming Dongtan. However, with the increasing impact of a series of factors such as reduced water and sediment in the upper reaches of the Yangtze River, reclamation utilization of tidal flats, invasion of alien plant species and disturbance of human production and construction activities ${ }^{[14]}$, the land use types in the east beach of Chongming have changed dramatically, which has threatened the habitat of migratory birds. Based on this, this paper takes Chongming Dongtan as the research area, based on the analysis of land use change in the Chongming Dongtan during 2002-2020, this paper evaluated the habitat quality spatio-temporal by InVEST model, and discussed the impact of land use change on habitat quality, aiming to restore the low-value area of habitat quality and coordinate the relationship between economic development and ecological environment protection. It is expected to provide some theoretical support for land management and ecological construction of Chongming Dongtan in the future.

\section{Data and Methods}

\subsection{General situations of research area}

Chongming Dongtan (121 $\left.433^{\prime}-122^{\circ} 05^{\prime} \mathrm{E}, 31^{\circ} 24^{\prime}-31^{\circ} 39^{\prime} \mathrm{N}\right)$, located in the north of Shanghai and the easternmost part of Chongming Island, was deposited by a huge amount of sediment transported by the runoff of the Yangtze River under the interaction of the river and sea. Based on Chongming Dongtan Wetland Reserve and adjacent agricultural reclamation areas, the study area is buffered 5 kilometers to the west (Figure 1), with a total area of 552.17 square 
kilometers.

Chongming Dongtan belongs to the subtropical monsoon climate, humid climate, four distinct seasons. The annual average temperature is $15^{\circ} \mathrm{C}-16^{\circ} \mathrm{C}$, the extremely high temperature is $37.3^{\circ} \mathrm{C}$, the extremely low temperature is $-10.5^{\circ} \mathrm{C}$, the annual average frost-free period is about 320 days, the annual average rainfall is $900 \mathrm{~mm}-1050 \mathrm{~mm}$, mainly from April to September, and the relative humidity of the air is $82 \%$. Chongming Dongtan is formed by sediment accumulation. The terrain is flat and the elevation is between 3.2 and 4.4 meters. Generally, it is higher in the west and lower in the east, with little difference in elevation. From west to East, it can be divided into high tide beach, middle tide beach and low tide beach. In 1992, Chongming Dongtan Wetland was listed in China Protected Wetlands List. In 1998, Chongming Dongtan Wetland Reserve was established. In 2002, Chongming Dongtan Wetland Reserve and its surrounding constructed wetlands were listed as international important wetlands, and in 2005, it was upgraded to national nature reserve.

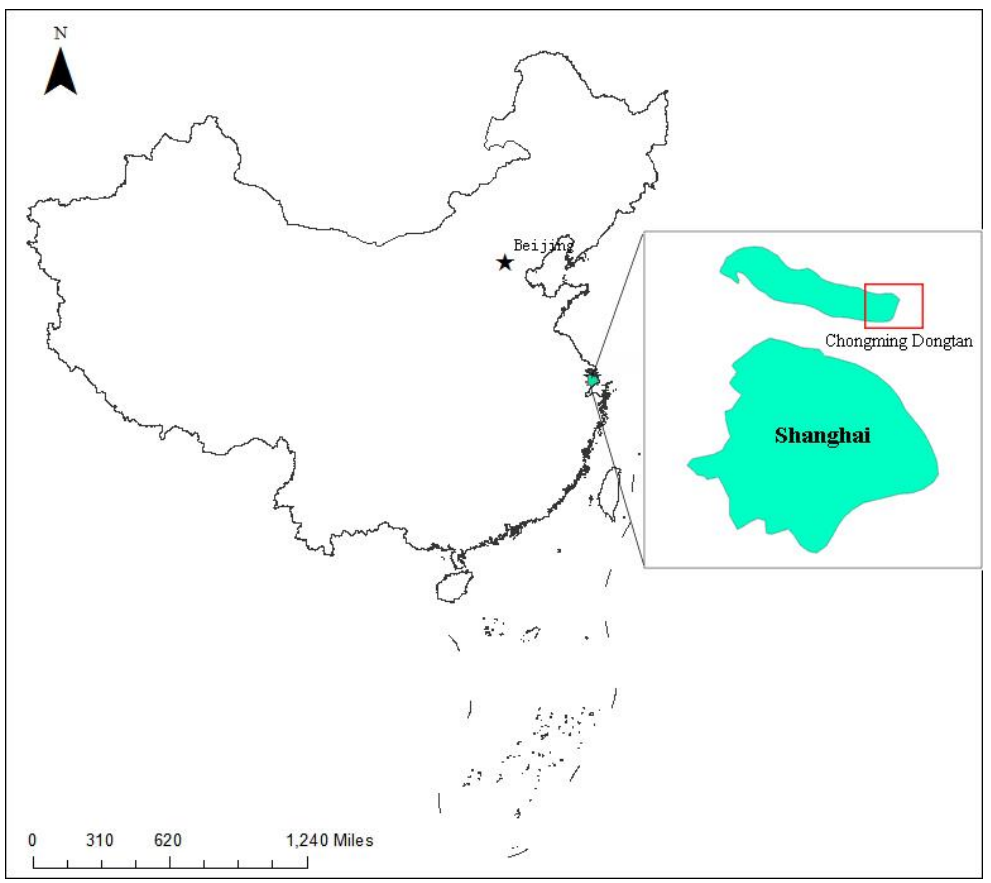

Fig.1 Location map of Chongming Dongtan

\subsection{Data source and processing}

The land use data in this paper $(2002,2012,2020)$ are all from the geospatial data cloud platform (http://www.gscloud.cn) of Computer Network Information Center, Chinese Academy of Sciences. The spatial resolution of the data is $30 \mathrm{~m}$, and the cloud coverage is less than $5 \%$. According to the Classification of Land Use Status (GB/T21010-2017) and the purpose of the study, the land use types in the study area can be divided into eight categories: reed beach, grass beach, bare beach, water area, dry land, paddy field, woodland and construction land. The standard image was generated by the steps of band combination, radiation correction, image fusion and image cropping with ENVI5.2 software, and the land use status map of the three phases was obtained by human-computer interactive interpretation method (Figure 2). After classification was completed, the error matrix was established with ENVI software and the Kappa coefficient was calculated. The results of Kappa coefficient in 2002, 2012 and 2020 are 0.8828, 0.8733 and 
1110.8939 , respectively, which indicates that the classification results are authentic and reliable.

112 According to the accuracy evaluation of 85 GPS verification points collected from the field, the 113 average overall accuracy of land cover types can reach $91.25 \%$, and the classification accuracy is 114 high, which provides a guarantee for the follow-up research.

115
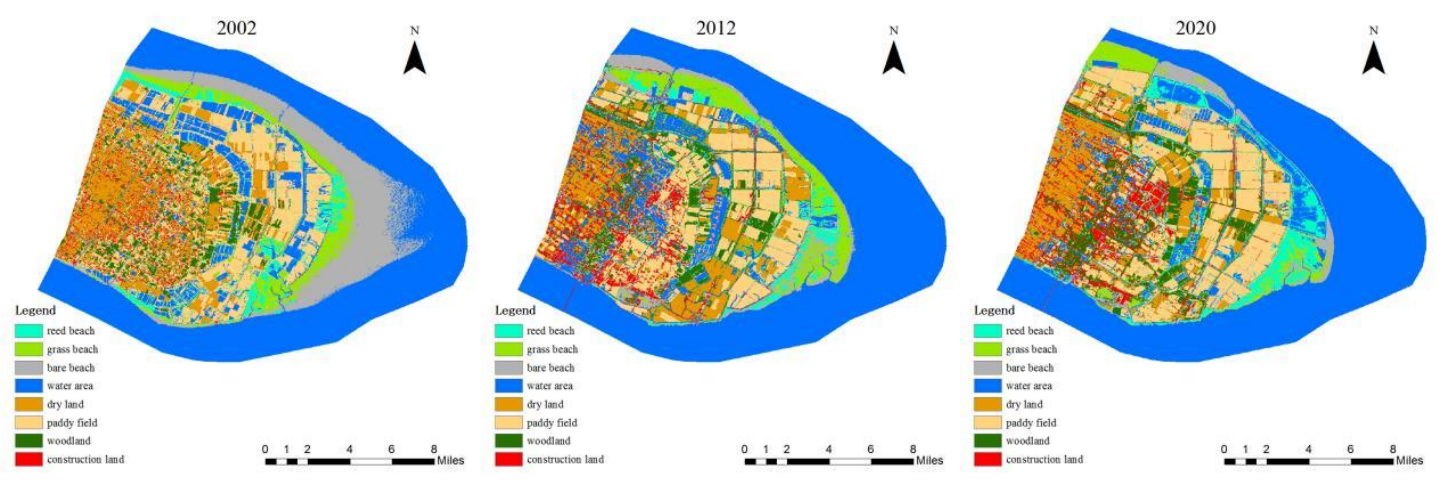

Fig.2 The distribution of land use of Chongming Dongtan

\subsection{Research methods}

\subsubsection{Single land use dynamic degree}

The single land use dynamic degree represents the quantitative change rate of a certain land use type in a certain period of time in a region ${ }^{[15]}$, and its calculation formula is as follows:

$$
K=\frac{U_{b}-U_{a}}{U_{a}} \times \frac{1}{T} \times 100 \%
$$

In the formula, $K$ represents the single land use dynamic degree of a certain land type; $U_{a}$ and $U_{b}$ and represent the area of a certain land use type in the early and late stages; $T$ is the length of a given period of time; $K$ value reflects the change rate of a specific land use type in a given period of time.

\subsubsection{Land use degree}

The degree of land use can not only reflect the law of land use change, but also reflect the influence of human activities and natural environment on land use ${ }^{[16]}$. According to the land use grading index method and land use degree model proposed by Liu Jiyuan et al., land use is divided into four grades ${ }^{[17]}$, as shown in Table 1.

\begin{tabular}{|c|c|c|c|c|}
\hline & Unused land class & $\begin{array}{c}\text { Forests, grasses and water } \\
\text { class }\end{array}$ & Land grade in agriculture & Urban settlements class \\
\hline & & reed beach & & \\
\hline Land uses type & bare beach & $\begin{array}{l}\text { grassland } \square \text { woodland } \square \text { wat } \\
\text { er area }\end{array}$ & dry land、 paddy field & construction land \\
\hline Grading index & 1 & 2 & 3 & 4 \\
\hline
\end{tabular}

The model of land use degree is as follows:

$$
L_{a}=100 \times \sum_{i=1}^{n} A_{i} \times C_{i} \quad L_{a} \in(100,400)
$$


$L_{a}$ is the comprehensive index of land use degree in the study area; $A_{i}$ is the grade $\mathrm{i}$ index of land use degree in the study area; $C_{i}$ is the area percentage of grade i land use type in the study area.

\subsubsection{InVEST habitat quality model}

InVEST habitat quality assessment model is based on land use type data to evaluate habitat quality. In this study, this module was used to evaluate the spatial and temporal evolution of habitat quality in Chongming Dongtan in 2002, 2012 and 2020.

(1) The calculation formula of habitat degradation degree $\left(D_{x j}\right)^{[18]}$ is as follows:

$$
\begin{gathered}
D_{x j}=\sum_{r=1}^{R} \sum_{y=1}^{Y_{r}}\left(\frac{\omega_{r}}{\sum_{r=1}^{R} \omega_{r}}\right) r_{y} i_{r x y} \beta_{x} S_{j r} \\
i_{r x y}=1-\left(\frac{d_{x y}}{d_{r \max }}\right) \text { if linear } \\
i_{r x y}=\exp \left(-\left(\frac{2.99}{d_{r \max }}\right) d_{x y}\right) \text { if exponential }
\end{gathered}
$$

In formula (3) to (5), $D_{x j}$ represents the degradation degree of the total threat level of grid unit $\mathrm{x}$ in land use type $\mathrm{j} ; \mathrm{r}$ is the threat factor; $\mathrm{Y}_{\mathrm{r}}$ represents the total number of all grid units of threat factor $\mathrm{r}$ in the current land use/cover type map; $\omega_{r}$ is the weight coefficient of the threat factor, and its value is $[0,1] . r_{y}$ represents the number of threat factors in all grid units of threat factors in the current land use/cover type map; B is the level at which law/institution/society/nature protects each unit from interference, with a value of $[0,1]$ (this factor is not taken into account in this paper, so the model will automatically assign this value as 1 at run time). $S_{j r}$ represents the sensitivity of each land use type to different threat factors. $i_{\mathrm{r} x y}$ represents the influence of threat factors on the whole space, $d_{x y}$ represents the linear distance between grid units $\mathrm{x}$ and $\mathrm{y}$, and $d_{r \max }$ represents the maximum image distance that each threat factor can reach in the space.

(2) The calculation formula of habitat quality ${ }^{[18]}$ is as follows:

$$
Q_{x j}=H_{j}\left(1-\left(\frac{D_{x j}^{z}}{D_{x j}^{z}+k^{z}}\right)\right)
$$

In Equation (6), $Q_{x j}$ represents the habitat quality of grid unit x in land use type $\mathrm{j} ; H_{j}$ represents Habitat (suitability) values of different land use types $\mathrm{j}$; $D_{x j}$ represents the degradation degree of the total threat level of raster unit $x$ in land use type $j$; $z$ is a fixed value provided by the system, with a value of $2.5 ; \mathrm{k}$ is the half-saturation constant.

The operation of this module needs to obtain four kinds of necessary data, which are the current land use/cover map, threat data, sensitivity of land cover type to each threat factor, half-saturation constant. On the basis of invest model manual and related research [19-23], reed beach, dry land, paddy field and construction land were selected as threat factors in this study. According to the actual situation of the study area and experts' suggestions, threat factors and sensitivity of threat factors were assigned (Table 2 and Table 3 ). 


\begin{tabular}{cccc}
\hline Threat factor & $\begin{array}{c}\text { Maximum distance of } \\
\text { stress }(\mathrm{km})\end{array}$ & Weight & Spatial decay function \\
\hline reed beach & 0.5 & 0.2 & exponential \\
dry land & 2 & 0.4 & exponential \\
paddy field & 2 & 0.4 & exponential \\
\hline
\end{tabular}

Table 3 Sensitivity of various land use types to ecological threats

\begin{tabular}{|c|c|c|c|c|c|}
\hline Land use type & Habitat suitability & reed beach & dry land & construction land & paddy field \\
\hline reed beach & 1 & 0 & 0.2 & 0 & 0.2 \\
\hline grass beach & 1 & 0.2 & 0 & 0 & 0 \\
\hline bare beach & 0.8 & 0.5 & 0 & 0 & 0 \\
\hline water area & 0.8 & 0 & 0 & 0.5 & 0 \\
\hline dry land & 0 & 0.2 & 0 & 0.5 & 0.6 \\
\hline paddy field & 0 & 0.2 & 0.6 & 0.5 & 0 \\
\hline woodland & 0 & 0 & 0.2 & 0.5 & 0.2 \\
\hline construction land & 0 & 0 & 0 & 0 & 0 \\
\hline
\end{tabular}

Note: Habitat suitability is assigned according to the contribution of each habitat type to the maintenance of main animal and plant resources in the study area.

\section{Results and Analysis}

\subsection{Analysis of land use change}

In the past 18 years, the changes of land use in Chongming east beach are different (Table 4). Water area is the main type of land use in the study area, accounting for more than $39 \%$ in each of the three periods, mainly including seawater, aquaculture water, rivers and ditches. Paddy field in the study area decreased first and then increased, with an overall increase of $375.41 \mathrm{hm}^{2}$, accounting for $0.68 \%$ of the study area; The dry land increased first and then decreased, and the net decreased area and proportion were $832.95 \mathrm{hm}^{2}$ and $1.51 \%$ respectively; The area of bare beach decreased significantly and the change range was the largest, with a total decrease of $5310.31 \mathrm{hm}^{2}$, which reached 9.62\%; Woodland increased continuously, and the net increase area and increase rate were $1004.47 \mathrm{hm}^{2}, 1.82 \%$, respectively; The grassland area increased first and then decreased, and decreased by $789.39 \mathrm{hm}^{2}$, accounting for $1.43 \%$ of the study area; The reed beach decreased first and then increased, with an overall increase of $1181.7 \mathrm{hm}^{2}$, accounting for $2.14 \%$ of the study area; The area of construction land increased continuously, and the net increase area and growth rate were $1598.15 \mathrm{hm}^{2}, 2.89 \%$ respectively. 


\begin{tabular}{|c|c|c|c|c|c|c|}
\hline \multirow{2}{*}{ Land use type } & \multicolumn{2}{|c|}{2002} & \multicolumn{2}{|c|}{2012} & \multicolumn{2}{|c|}{2020} \\
\hline & Area $/ \mathrm{hm}^{2}$ & Ratio/\% & Area $/ \mathrm{hm}^{2}$ & Ratio/\% & Area $/ \mathrm{hm}^{2}$ & Ratio/\% \\
\hline reed beach & 2033.19 & 3.68 & 2007.54 & 3.57 & 3214.89 & 5.82 \\
\hline grass beach & 3228.21 & 5.85 & 3592.44 & 6.39 & 2438.82 & 4.42 \\
\hline bare beach & 7277.13 & 13.18 & 2205.9 & 3.92 & 1966.82 & 3.56 \\
\hline water area & 21840.84 & 39.55 & 26172.99 & 46.56 & 24613.4 & 44.58 \\
\hline dry land & 5555.52 & 10.06 & 5702 & 10.14 & 4722.57 & 8.55 \\
\hline paddy field & 10368.81 & 18.44 & 10084.46 & 17.94 & 10744.22 & 19.46 \\
\hline woodland & 2955.78 & 5.35 & 3357.27 & 5.97 & 3960.25 & 7.17 \\
\hline construction land & 1957.95 & 3.55 & 3094.83 & 5.51 & 3556.1 & 6.44 \\
\hline
\end{tabular}

The single dynamic degree of land use type indicates the speed of land use change. The change of single land use dynamic degree in Chongming Dongtan from 2002 to 2020 shows (Figure 3) that from 2002 to 2012, bare beach and construction land have the fastest change in land use area, with dynamic degrees of $-6.97 \%$ and $5.81 \%$ respectively; However, from 2012 to 2020 , reed beach and grass beach had the fastest change in land use area, with dynamic degrees of $7.52 \%$ and $-4.01 \%$ respectively. On the whole, reed beach, water area, paddy field, woodland and construction land showed an increasing trend, and the dynamic degrees were $3.23 \%, 0.71 \%$, $0.20 \%, 1.89 \%$ and $4.53 \%$ respectively. On the other hand, grass beach, bare beach and dry land showed a decreasing trend, and the dynamic degree was $-1.36 \%,-4.05 \%$ and $-0.83 \%$, respectively. The results show that construction land is the fastest increasing land use area, while the bare beach is the fastest decreasing land use area, which is closely related to the increase of population, the reclamation of tidal flat and the invasion of alien plant species in Chongming Dongtan since the new century.

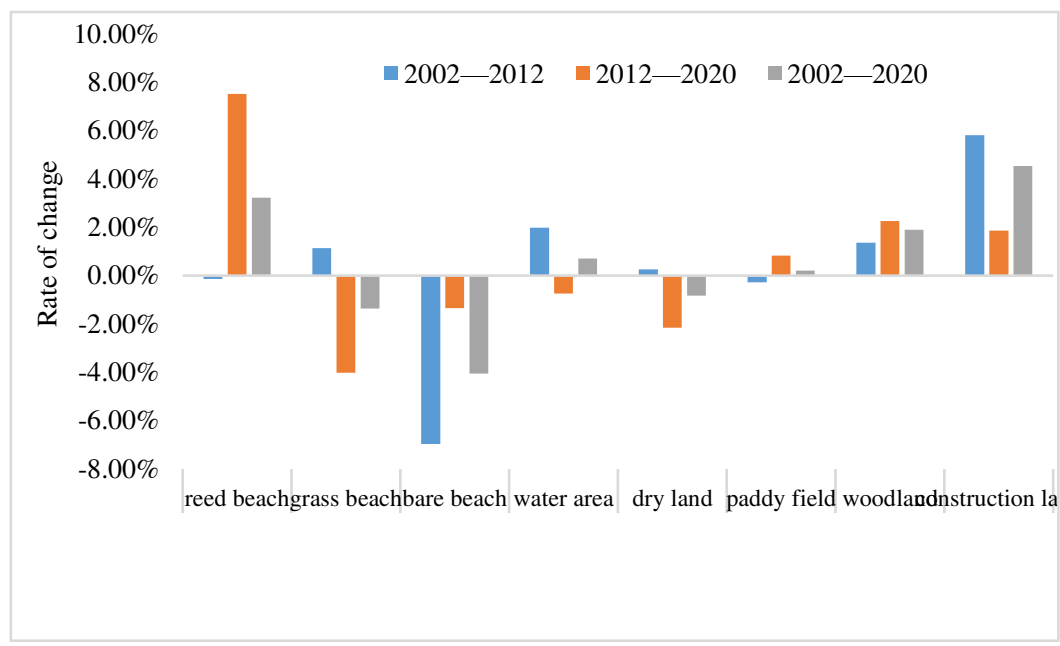

Fig.3 Change of Single land use dynamic degree in Chongming Dongtan from 2002 to 2020

In order to fully understand the structural characteristics of land use change in Chongming Dongtan during this period, the land use transfer matrix (Table 5) was constructed. From 2002 to 2012, reed beach and grass beach were transformed into each other in this stage. and the area of 
reed beach land converted to grass beach land $\left(844.84 \mathrm{hm}^{2}\right)$ was larger than that of grass beach land converted to reed beach land $\left(696.51 \mathrm{hm}^{2}\right)$. This was mainly due to Spartina alterniflora began to invade the living range of reed and Scirpus mariquete since it was introduced in the late 1990s, After the introduction of Spartina alterniflora, the invasion threat began to appear gradually. The bare beach is mainly transferred to grass beach and reed beach, and it is still the reserve living space of beach vegetation. The area transferred from water area to paddy field reached $754.42 \mathrm{hm}^{2}$, accounting for $41.00 \%$ of the amount transferred from water area, mainly from the previously reclaimed and uncultivated areas. The area of cultivated land transferred to water area was $1319.59 \mathrm{hm}^{2}$, which is mainly the result of developing aquaculture and aquatic crops in Dongtan. The conversion area of woodland is small and the retention rate is high, and the main types of conversion are construction land, dry land and paddy field. The construction land increased rapidly at this stage, and the transferred increased area was $1720.92 \mathrm{hm}^{2}$, in which the proportion of dry land and paddy field was up to $36.15 \%$ and $42.11 \%$, respectively.

\begin{tabular}{|c|c|c|c|c|c|c|c|c|c|}
\hline Year & Land use type & reed beach & grass beach & bare beach & water area & dry land & paddy field & woodland & construction land \\
\hline $2002-$ & reed beach & 476.96 & 844.84 & 172.91 & 189.33 & 60.81 & 240.63 & 27.05 & 20.66 \\
\hline \multirow[t]{7}{*}{2012} & grass beach & 696.51 & 1354.10 & 295.04 & 420.76 & 41.91 & 354.03 & 51.92 & 13.94 \\
\hline & bare beach & 584.59 & 1245.44 & 1052.26 & 4169.08 & 30.84 & 142.38 & 15.82 & 36.72 \\
\hline & water area & 224.02 & 108.00 & 652.50 & 20000.58 & 38.05 & 754.42 & 54.51 & 8.76 \\
\hline & dry land & 3.24 & 4.13 & 9.48 & 274.43 & 4006.70 & 238.46 & 396.91 & 622.17 \\
\hline & paddy field & 10.66 & 16.97 & 9.37 & 1045.16 & 548.61 & 7565.25 & 448.14 & 724.65 \\
\hline & woodland & 8.01 & 6.83 & 11.76 & 69.44 & 216.06 & 186.77 & 2162.89 & 294.02 \\
\hline & construction land & 3.55 & 12.13 & 2.58 & 4.21 & 259.02 & 102.52 & 200.03 & 1373.91 \\
\hline $2012-$ & reed beach & 688.80 & 273.39 & 108.51 & 253.26 & 36.72 & 509.91 & 79.23 & 57.52 \\
\hline \multirow[t]{7}{*}{2020} & grass beach & 1240.92 & 908.82 & 380.28 & 336.39 & 63.19 & 585.48 & 33.68 & 36.56 \\
\hline & bare beach & 381.38 & 513.93 & 808.24 & 249.90 & 16.35 & 174.91 & 28.27 & 32.62 \\
\hline & water area & 877.60 & 655.91 & 643.19 & 23003.91 & 14.60 & 857.30 & 68.00 & 26.10 \\
\hline & dry land & 8.33 & 15.67 & 7.80 & 201.38 & 3585.72 & 321.43 & 661.86 & 398.84 \\
\hline & paddy field & 6.34 & 41.39 & 8.71 & 431.33 & 527.43 & 7806.98 & 422.77 & 338.47 \\
\hline & woodland & 6.97 & 17.97 & 7.38 & 85.75 & 308.64 & 322.95 & 2500.00 & 107.23 \\
\hline & construction land & 4.21 & 10.82 & 2.13 & 20.94 & 168.38 & 164.55 & 165.77 & 2557.01 \\
\hline
\end{tabular}

Compared with the previous stage, from 2012 to 2020, the area of reed beach to grass beach $\left(273.39 \mathrm{hm}^{2}\right)$ is much smaller than that of grass beach to reed beach $\left(1240.92 \mathrm{hm}^{2}\right)$, which is mainly due to the large-scale management of Spartina alterniflora in Dongtan area, which makes the reed beach gradually recover. The transfer area of bare beach to reed beach and grass beach was $895.31 \mathrm{hm}^{2}$, which was $934.72 \mathrm{hm}^{2}$ less than that of the previous stage. The water area transferred into reed beach and grass beach increased by $1201.49 \mathrm{hm}^{2}$ compared with the previous stage. Dry land and paddy field still maintained a relatively high unchanged area, accounting for $68.94 \%$ and $81.46 \%$ of the total area, respectively. Water area accounted for a relatively large proportion of the converted area of paddy field, which was mainly due to the fact that part of the cultivation ponds were converted into cultivated land after reclamation. Forestland was mainly transferred to dry land and paddy field, accounting for $36.02 \%$ and $37.69 \%$, respectively. The transfer out area of 
construction land is small, and the main types of transfer out are cultivated land and woodland, which is mainly due to the land reclamation caused by the withdrawal of homestead. In the transfer type of construction land, cultivated land and forest land are still the main sources.

\subsection{Impact of land use change on habitat}

Based on the land use data of three periods, the average habitat quality index and habitat degradation degree were calculated based on formula (3) - (6). and the habitat degradation degree was divided into five grades: basically unchanged, weak degradation, moderate degradation, high degradation and strong degradation; ArcGIS software was used to make statistics on the above calculation results, and combined with the land use degree index in Figure 4, the response of habitat change to land use change in Chongming Dongtan was analyzed.

\subsubsection{Temporally, the impact of land use change on habitat}

From the perspective of time change (Table 6), from 2002 to 2020 , the area of the basically unchanged level of habitat quality degradation continued to decline, with a decline rate of $4.6 \%$. However, the area of weak degradation level of habitat quality increased continuously, and the increasing area and proportion were $4072.5 \mathrm{hm}^{2}$ and $7.37 \%$, respectively. This is mainly due to the area of the basically unchanged level of habitat quality degradation was transferring to the weak degradation level, It leads to the continuous increase of its area. The basically unchanged level of habitat quality degradation and the weak degradation level of habitat quality belong to the low value area of habitat quality degradation, which can be classified as one kind of research. From 2002 to 2020 , the sum of the two areas accounted for more than $70 \%$ of the total area, which indicated that the overall habitat quality of Chongming Dongtan is good, and the degradation degree of habitat quality is low. This is closely related to the small proportion of construction land area (all less than 7\%) and the weak disturbance of human activities in Chongming Dongtan. The area proportion of moderate degradation and high degradation habitats showed the same trend of increasing at first and then decreasing. The increase of habitat degradation area in the former stage was mainly related to the increase of the inflow area of construction land and the increase of dry land and paddy fields as threat factors in the study area. The reduction of habitat degradation area in the latter stage was mainly related to the implementation of the ecological control of Spartina alterniflora and bird habitat optimization project in Chongming Dongtan since 2013, which artificially improved the habitat quality of bird habitat in the reserve. The area of strong degradation habitats has been increasing year by year, which is directly related to the increase of a series of human disturbance factors such as the increase of population and human production and construction activities in Chongming Dongtan. However, the proportion of strong degradation habitats is lower than $10 \%$, which indicates that the protection of the habitat in Chongming Dongtan is relatively good and the degradation of habitat quality is under control.

Secondly, combining with the land use degree index (Figure.4), it was found that the land use degree index increased continuously from 222.75 to 237.33 during 2002-2012, while the average habitat quality index decreased from 0.5171 in 2002 to 0.4874 in 2020 , and the proportion of strong degradation level area of habitat quality also increased from 5.19\% to $8.07 \%$; However, as the increase rate of land use degree index decreased after 2012, the area proportion of moderate degradation and high degradation habitat quality decreased, while the area proportion of basically unchanged and weak degradation habitat quality increased, which fully indicated that there was correlation between land use degree and habitat quality change. In a sense, it is revealed that land 
use change has a direct impact on the evolution of habitat quality.

Table 6 Degraded area, proportion and average value of habitat quality of different grades in Chongming

Dongtan

\begin{tabular}{ccccccc}
\hline \multirow{2}{*}{$\begin{array}{c}\text { Degradation grade of habitat } \\
\text { quality }\end{array}$} & \multicolumn{2}{c}{2002} & \multicolumn{2}{c}{2012} & \multicolumn{2}{c}{2020} \\
\cline { 2 - 7 } & Area/ $/ \mathrm{hm}^{2}$ & Ratio/\% & Area/ $\mathrm{hm}^{2}$ & Ratio/\% & Area $/ \mathrm{hm}^{2}$ & Ratio/\% \\
\hline Basically unchanged & 33681.06 & 61.00 & 30822.66 & 55.82 & 30589.85 & 55.40 \\
Weak degradation & 8149.77 & 14.76 & 8274.96 & 14.99 & 12222.27 & 22.13 \\
Moderate degradation & 5261.85 & 9.53 & 6797.79 & 12.31 & 4105.67 & 7.44 \\
High degradation & 5256.9 & 9.52 & 6292.8 & 11.40 & 3841.22 & 6.96 \\
Strong degradation & 2867.76 & 5.19 & 3029.22 & 5.49 & 4458.04 & 8.07 \\
\hline Average habitat quality index & \multicolumn{2}{c}{0.5171} & \multicolumn{2}{c}{0.5125} & \multicolumn{2}{c}{0.4874} \\
\hline
\end{tabular}

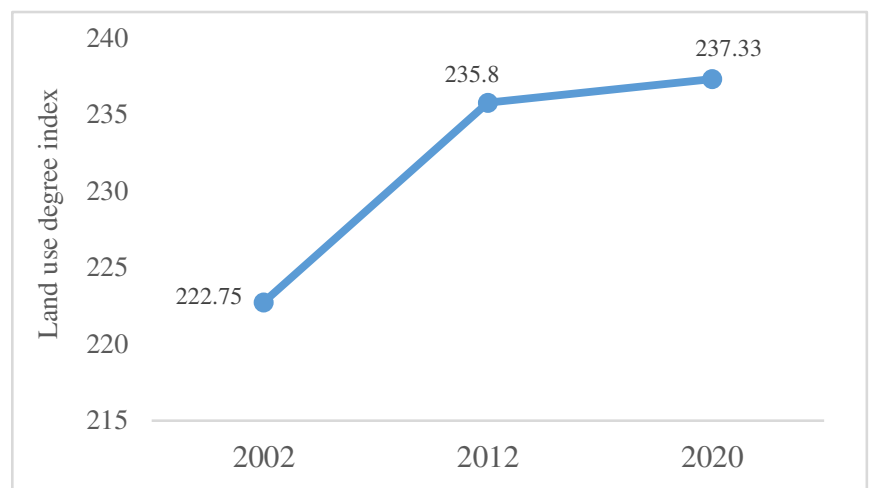

Fig.4 Land use degree index change of Chongming Dongtan from 2002 to 2020

\subsubsection{Spatially, the impact of land use change on habitat}

From the perspective of spatial pattern change (Figure.5), the habitat degradation degree of Chongming Dongtan from 2002 to 2020 has a trend of high in the East and low in the west, spreading from the center to the surrounding, and the spatial performance is the expansion of degraded areas. The area of basically unchanged and weak degradation habitats is mainly located in the peripheral waters of Chongming Dongtan and the eastern protection area. These areas are mainly reed beach, grass beach and bare beach, which are close to the ocean and are rich in biodiversity. The moderate degradation level of habitat quality was mainly distributed in the coastal area, and the main land use types were cultivated land and woodland. The high and strong degradation level of habitat quality mainly distributed in the center of Chongming Dongtan, where there is a large population density, intensive construction land for urban residents, strong land use and development intensity, and more disturbance from human activities. From 2002 to 2012, it can be found that the area of high and strong degradation of habitat quality increased significantly, combined with the above land use transfer matrix, the area of construction land increased at this stage, secondly as threat factors of upland and paddy field area is also increasing, indicates that with the change of land use, habitat quality appear the corresponding degradation; Compared with 2002 and 2012, it can be found that the area of strong degradation level of habitat quality in 2020 is still expanding, but the area of moderate and high degradation of habitat quality is significantly reduced, and the reduced area is mainly in the nature reserve, which indicates that the moderate 
and high degradation of habitat quality in the nature reserve is transferred to the weak degradation of habitat quality. The habitat quality of the nature reserve has been effectively improved, which is mainly due to the implementation of Spartina alterniflora ecological control and bird habitat optimization project in Chongming Dongtan. The improvement of bird habitat quality is promoted through artificially changing land use, which also reveals that land use is the main driving factor of habitat quality change.
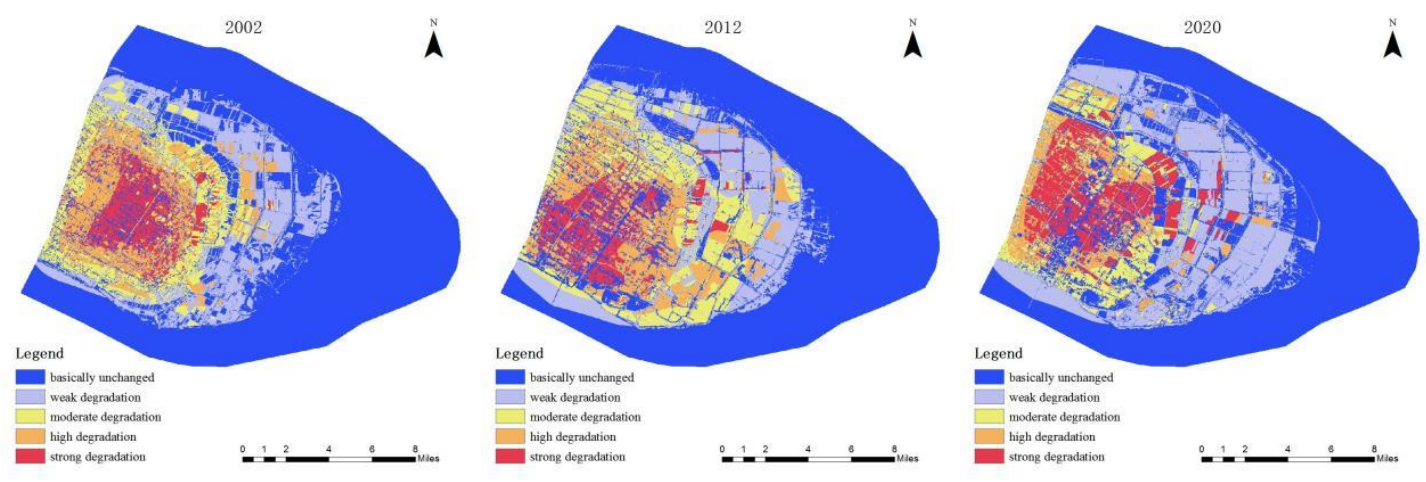

Fig.5 Spatial distribution of habitat degradation degree in Chongming Dongtan from 2002 to 2020

\section{Discussion and Conclusions}

(1) The main land use types in the study area are water area and cultivated land, followed by woodland, reed beach, grass beach, bare beach and construction land. Among them, the change of bare beach and construction land was more intense, and the bare beach continued to decrease, with a reduction ratio of up to $9.62 \%$. The area of construction land is increasing continuously, and its increasing speed begins to slow down after 2012. The increase is mainly from the conversion of surrounding arable land.

(2) In terms of time change, the degradation of habitat quality in Chongming Dongtan has been gradually improved from the worsening trend in the past 18 years. From 2002 to 2012, the degradation of habitat quality was relatively obvious. After 2012, although the area of strong degradation habitats continued to increase, with the decrease of the proportion of the area with moderate and high degradation level of habitat quality, the area with basically unchanged and weak degradation level of habitat quality increased. As well as the decrease of dynamic degree of construction land, Spartina alterniflora management and bird habitat optimization, the grass land with low habitat suitability changed to reed land with high habitat suitability, which promoted the improvement of habitat quality in Chongming Dongtan. It can be seen that the change of habitat quality is closely related to the inter-conversion of land use.

(3) In terms of spatial distribution, the habitat degradation degree of Chongming Dongtan has a trend of high in the East and low in the west, spreading from the center to the surrounding. The main reasons for the high degradation of habitat quality in the east are the high population density, the intensive construction land for urban residents and the high intensity of land use and development in this region. However, the low degradation degree of habitat quality is due to the fact that it is located in the nature reserve with less interference from human activities.

\section{References}

[1] Li Shengpeng, Liu Jianling, Lin Jin et al. Spatial and temporal evolution of habitat quality in Fujian Province, 
China based on the land use change from 1980 to 2018[J]. Chinese Journal of Applied Ecology, 2020, 31(12): 4080-4090.

336 [2] Yang Li, Dong Bin et al. Habitat suitability change of water birds in Shengiinhu National Nature Reserve, Anhui Province[J]. Journal of Lake Science, 2015, 27(06): 1027-1034.

338 [3] Bao Yubin, Liu Kang et al. Effects of Land Use Change on Habitat Based on InVEST Model -Taking Yellow 339 River Wetland Nature Reserve in Shaanxi Province as an Example[J]. Arid Zone Research, 2015, 32(03): 622-629.

340 [4] Wu Nan, Chen Hongfeng et al. Spatio - temporal Evolution Characteristics of Habitat Quality Based on Land 341 Cover Change in Anhui Province[J]. Resources and Environment in the Yangtze Basin, 2020, 29(05): 1119-1127.

342 [5] Yohannes Hamere et al. Spatio-temporal changes in habitat quality and linkage with landscape characteristics

343 in the Beressa watershed, Blue Nile basin of Ethiopian highlands[J]. Journal of environmental management, 2020, $344 \quad 281: 111885-111885$.

345 [6] Lee Dongjin and Jeon Seong Woo. Estimating Changes in Habitat Quality through Land-Use Predictions: 346 Case Study of Roe Deer (Capreolus pygargus tianschanicus) in Jeju Island[J]. Sustainability, 2020, 12(23) : $347 \quad 10123-10123$.

348 [7] David M. Mushet and Jordan L. Neau and Ned H. Euliss. Modeling effects of conservation grassland losses on 349 amphibian habitat[J]. Biological Conservation, 2014, 174 : 93-100.

350 [8] Jia Yanyan, Wang Shaojie et al. Land use change and its correlation with habitat quality in high efficiency 351 Eco-economic zone of Yellow River Delta[J]. Bulletin of Soil and Water Conservation, 2020, 40(06): $352 \quad 213-220+227+330$.

353 [9] Liu Fangtian, Xu Erqi et al. Comparison of spatial-temporal evolution of habitat quality between Xinjiang 354 Corps and Non-corps Region based on land use[J]. Chinese Journal of Applied Ecology, 2020, 31(07): 2341-2351. 355 [10]Wang Geng, Wang Jiawen et al. Study on the Impact of Land Use Change on Habitat Quality in Dandong 356 Coastal Area[J]. Ecology and Environmental Sciences, 2021, 30(03): 621-630.

357 [11]Huang Muyi, Yue Wenze et al. Spatial-temporal evolution of habitat quality and analysis of landscape patterns 358 in Dabie Mountain area of west Anhui province based on InVEST model[J]. Acta Ecologica Sinica, 359 2020,40(09):2895-2906.

360 [12]Han Yanli, Chen Kelong et al. Evaluation on the Impact of Land Use Change on Habitat Quality in Qinghai 361 Lake Basin[J]. Ecology and Environmental Sciences, 2019, 28(10):2035-2044.

362 [13] Tian Bo, Zhou Yunxuan et al. A GIS and remote sensing-based analysis of migratory bird habitat suitability for 363 Chongming Dongtan Nature Reserve, Shanghai[J]. Acta Ecologica Sinica, 2008(07):3049-3059.

364 [14]Kuang Runyuan, Zhou Yunxuan et al. Spatial fuzzy comprehensive evaluation of bird habitat suitability in 365 Chongming Dongtan[J]. Resources and Environment in the Yangtze Basin, 2009, 18(03): 229-233.

366 [15]Li Xiufen, Liu Limin et al. Land use change dynamics and driving forces of the vulnerable ecological region 367 in north-western Shanxi Province, China[J]. Chinese Journal of Applied Ecology, 2014, 25(10): 2959-2967.

368 [16]Zhu Huiyi, Li Xiubin et al. Discussion on the index method of regional land use change[J]. Acta Geographica 369 Sinica, 2003, (05): 643-650.

370 [17]Zhuang Dafang, Liu Jiyuan et al. Study on the regional differentiation model of land use degree in China[J]. 371 Journal of Natural Resources, 1997(02):10-16.

372 [18]Ren Han. A Study on the Change of Habitat Quality in the Qi River Basin of Taihang Mountain Based on 373 LUCC[D]. Henan University, 2018.

374 [19]TALLIS H T, RICKETTS T, GUERRY A D, et al. InVEST VERSION User's Guide [M/OL]. Integrated 375 Valuation of Environmental Services and Tradeoffs. Stanford: The Natural Capital Project, 2016.

376 [20]Liang Peng et al. Research on ecological risk assessment in land use model of Shengjin Lake in Anhui 377 province, China[J]. Environmental Geochemistry and Health, 2019, 41(6) : 2665-2679. 


\section{Acknowledgments}

386 This paper was funded by National Natural Science Foundation of China ( NSFC , 387 32071600,41571101）, Natural Science Research Projects of Anhui Higher Education Institutions 388 (KJ2020A0112).

\section{Author information}

390 First Author:Sheng Li, born in October, 1995. Master degree candidate. E-mail: 391 1780006315@qq.com.

392 *Corresponding author : Bin Dong, born in September 1970, professor, doctoral supervisor. The 393 research direction for the mapping and $3 \mathrm{~S}$ technology and application. E-mail: 394 dbhy123@sina.com;

395 The authors declare that they have no conflict of interest. 